AUthors' REPLY, - We are grateful to Dr Martin and $\mathrm{Mr}$ Tweedle for their comments. It is our contention that this complication, which has been noted before, ${ }^{\prime}$ is probably underrecognised rather than rare. We do not advocate doing therapeutic biliary endoscopy as a day case procedure, and it is certainly not our practice to do this. Other complications such as pancreatitis and septicaemia may also present after four to six hours, and our patients often come from far away as tertiary referrals.

We use a similar technique to that of Dr Martin and $\mathrm{Mr}$ Tweedle, using an electrosurgical unit with a power output of 30 watts, although the output may have to be increased in patients with longstanding choledocholithiasis and fibrosis at the lower end of the bile duct. We prefer a plain wired sphincterotome. Interestingly, our overall rate of bleeding after sphincterotomy $(3 \%)$ is virtually identical with that quoted by others, ${ }^{12}$ including Dr Martin and Mr Tweedle, who were among four authors who reported bleeding in six of 215 patients. ${ }^{2}$ It is not apparent why this bleeding may become overt late, but the need for vigilance remains clear.

A FINNIE I T GILMORE

Royal Liverpool Hospital

Liverpool L7 8XP

1 Goodall RJR. Bleeding after endoscopic sphincterotomy Ann R Coll Surg Engl 1985;67:87-8.

2 Leese T, Neoptolemos JP, Carr-Locke DL. Successes, failures, early complications and their management following endoscopic sphincterotomy: results in 394 patients from a single centre. Br f Surg 1985;72:215-9.

3 Hill J, Maxwell AJ, Tweedle DEF, Martin DR. Do measured parameters of blood clotting help predict haemorrhage after endoscopic sphincterotomy? [Abstract.] Gut 1990;31:A608.

\section{Preventing stroke among people of African or West Indian origin}

SIR,-Professor A G Shaper and his colleagues have clearly identified the major risk factors for stroke in the cohort of middle aged men that they studied; this will be of value when developing preventive strategies for stroke.' The possibility of certain ethnic groups being more at risk of hypertension, and consequently stroke, is not, however, addressed. Although the proportion of subjects at risk may have been small in the study areas, this factor has public health implications for preventing stroke. A community based stroke register in west Lambeth identified 18 first strokes in residents aged under 75 of African or West Indian origin. This represented $20 \%$ of the total number of strokes in a one year study. In the neighbouring district of Lewisham and north Southwark $11 \%$ of strokes were in these ethnic groups, whereas in Tunbridge Wells district no strokes were identified in these groups.

Black communities are at increased risk of stroke, mainly as a result of underlying hypertension. ${ }^{2}$ Morgan and Watkins have studied the beliefs of these groups regarding hypertension and their responses to antihypertensive treatment and found that less than half of them were compliant. Therefore, although hypertension can be prevented by controlling blood pressure, special consideration needs to be given to reducing the risk of stroke in the West Indian and African communities.

C D A WOLFE J WOODROW

Division of Community Health, E RICHARDSON

United Medical and Dental Schools of

London SE1 7EH

1 Shaper AG, Phillips AN, Pocock SJ, Walker M, Macfarlane PW Risk factors for stroke in middle aged British men. $B M$ 1991;302:1111-5. (11 May.)
2 Heyman A, Karp HR, Hevden S, Bartel A, Cassel JC, Tyroler $\mathrm{HA}$, el al. Cerebrovascular disease in the bi-racial population of Evans County, Georgia. Stroke 1971;2:509-17.

Morgan $\mathrm{M}$, Watkins CJ. Managing hypertension: beliefs and responses to medication among cultural groups. Foumal.of Sociology of Health and Illness 1988:10:561-78.

\section{Who should be offered prenatal screening for Down's syndrome?}

SIR, - In their excellent paper appraising prenatal screening for Down's syndrome $\mathrm{Mr}$ Trevor A Sheldon and Dr John Simpson cite analyses showing that such screening based on maternal age is cost beneficial at risk cut off points of around one in 200. 'Their appraisal of the "triple test" is based on the same premise - that is, that it should be cost beneficial. This means that the screening process should result in a cost that is less than or the same as the cost of care of people with Down's syndrome who would otherwise be born. Their analysis suggests that using the triple test for all pregnancies would be a more equitable way of offering amniocentesis to all women in the same risk band irrespective of age.

Economic analyses of other medical innovations, however, do not restrict themselves to the relatively simple neutrality of cost. The economic appraisal of breast cancer screening, ${ }^{3}$ for example, did not simply consider whether the screening process would be cheaper than the care of women with advanced breast cancer that would be prevented. It accepted that there was a cost of this advance in health care but that the cost of extra life years (the "utility") was similar to that for other services that were currently being provided.

It would, perhaps, be more appropriate to judge a prenatal screening programme on how its cost-utility compares with that of other services. Measuring utility in these circumstances is not without problems, but such analysis would probably indicate that it would be more equitable to make amniocentesis available to those faced with an even smaller risk.

J N PAYNF

Trent Regional Health Authority,

Sheffield S10 3TH

1 Sheldon TA, Simpson J. Appraisal of a new scheme for prenata screening for Down's syndrome. BMY 1991;302:1133-6. screening

2 Wald NJ, Cuckle HS, Demsem JW, et al. Maternal screening for Down's syndrome in early pregnancy. BMF 1988;297:883-7.

Department of Health and Social Security. Breast cancer screening. Report to the health ministers of England, Wales, Scotland and Northern Ireland by a working group chaired by Professor Sir Patrick Forrest. London: HMSO, 1986.

\section{Psychological factors in breast cancer}

SIR,-Drs Simon Lovestone and Thomas Fahy's throwaway closing remark hits upon the key problem in linking psychological factors with the development and prognosis of breast cancer: "Overemphasising a relationship might lead to self blame by patients whose disease relapses." In fact, the evidence is so tenuous (as is that for links to dietary fat) that one would hesitate to mention it to a patient for fear of provoking self blame and unwarranted lifestyle change. Yet here we encounter a vast corpus of popular belief, shared by many doctors and nurses, that psychological factors are significant and indeed crucial in the clinical course of this and other malignancies. The finger of blame then waves at anyone whose cancer betrays them as emotionally repressed, insufficiently life affirming, unecological, or otherwise sinning against contemporary spiritual fashion.

These beliefs teeter on a precarious scientific foundation, while being bouyed from above by the hot air balloon of faith. For every properly cautious review such as that by Drs Lovestone and Fahy there are a myriad of glib paperbacks, and it is these books that patients read, and their friends press upon them. Thus a typical offering from one Dr Siegel:

Sandy, who developed breast cancer, had a dream with three roads ahead of her. "She chose the path of life, and as she grew, her cancer shrank." By contrast Jan was an actress who lacked self esteem. "If I don't hear any applause, how do I know I'm lovable?" Sure enough she died of her breast cancer.

Susan Sontag describes how "theories that diseases are caused by mental states and can be cured by will power are always an index of how much is not understood about the physical terrain of a disease. Moreover there is a peculiarly modern predilection for psychological explanations of disease, as of everything else. Psychologising seems to provide control over the experiences and events (like grave illnesses) over which people have in fact little or no control." ${ }^{3}$ The nineteenth century "psychologising" of tuberculosis evaporated with the advent of streptomycin, only to attach itself to cancer, insanity, and recently to HIV and AIDS.

The interaction of psychological factors and life circumstance with physical illness merits further study. It may greatly influence how well people reshape and come to terms with their lives under the shadow of lethal disease: "living with" as opposed to "suffering from" or "dying of" the condition. But as to pathogenesis and prognosis, the null hypothesis has gone by default and is worth boldly restating: one's mental state does not of itself cause cancer, nor cause one to succumb to it.

Ackton Hospital,

Pontefract WF7 6

1 Lovestone $\mathrm{S}$, Fahy T. Psychological factors in breast cancer. BMF 1991;302:1219-20. (25 May.)

2 Siegel BS. Love, medicine and miracles. London: Arrow, 1989.

3 Sontag S. Illness as metaphor. London: Allen Lane, 1979.

\section{Secret ballots: a cure for apathy?}

SIR, - In a survey of voting procedures, I wrote to all the secretaries of the 200 active divisions of the BMA.

The response, from 123 divisions $(61 \cdot 5 \%)$, was amazing. In only 17 divisions had any form of secret ballot ever been held, and this included five ballots on recent changes in the NHS. In 106 divisions either no votes were ever taken or voting was by a show of hands or "nod of heads," as one northern practitioner remarked. Furthermore, 31 of the respondents volunteered complaints of apathy and poor attendance at BMA divisional meetings, although my questions had related only to ballots.

These results made me wonder if the level of apathy among BMA members was in any way related to the voting procedures used at meetings. Medicine is a hierarchical profession, with a tradition of deference to one's teachers and senior colleagues. Hitherto, it may well have been possible to achieve a consensus, but now we all have to face highly contentious issues, on which widely differing views are sincerely and strongly held. Who would risk their prospects of a partnership, further hospital post, or promotion by voting publicly against their superiors? Furthermore, how can those who represent the profession learn the true feelings and views of the membership on such divisive issues, other than through a secret ballot?

Is it any wonder that, fearful of expressing views or voting publicly and imperilling their future, 